ISSN: $1130-3743$

\title{
LA EDUCACIÓN MORAL EN ARANGUREN
}

\section{The moral education for Aranguren}

\author{
Joan C. RINCÓN VERDERA \\ Universitat de les Illes Balears. Facultad de Educación. Universidad de las Islas Baleares. \\ Campus Universitario. 07071 Palma de Mallorca
}

Fecha de aceptación del original: 1997

BIBLID [( 1130-3743) 9, 1997, 75-91]

RESUMEN

La educación moral del hombre constituye, en Aranguren, una pieza indispensable en la formación integral de su personalidad. Una educación moral, cívica y política. En este artículo nos ocupamos de la primera dimensión: el hombre como responsabilidad personal.

\section{ABSTRACT}

The moral education of man is for Aranguren a very important aspect in the integral formation of man's personality. A moral, civic and political education. In this article we study the first dimension: man as a personal responsibility.

\section{POSIBILIDAD DE LA EDUCACIÓN MORAL}

Es preciso saber, siguiendo en ello a los profesores Escámez y García ${ }^{1}$, si es posible hablar de educación moral en el hombre. Contestar a ello implica responder la siguiente pregunta: ¿está el hombre suficientemente capacitado para elegir entre el bien y el mal? Si la dimensión moral no existiera o pudiera reducirse

1. ESCÁmeZ, J. y GARCía, R.: "Educación moral", en VARIOS: Filosofía de la educación boy. Conceptos, autores, temas, Madrid, Dykinson, 1991, pp. 93 y 104. 
a otra dimensión humana, nos dicen estos autores, las cuestiones referentes a su educación o bien serían impertinentes o bien no serían necesarias. A lo largo de toda la teoría moral arangureniana se puede constatar que la persona posee un ámbito, irreductible a cualquier otro, que podemos caracterizar inequívocamente como moral ${ }^{2}$ : el ser bumano es estructural y radicalmente moral. Aranguren ha tratado el problema, incluso, desde su perspectiva más extrema, la de la negación del problema de la moralidad en los casos correspondientes al determinismo, al amoralismo y al relativismo moral. En todos y cada uno de ellos Aranguren llega a la conclusión de que la dimensión moral del hombre es ineludible 3 . Por lo tanto, si la esencia moral no desaparece tiene pleno sentido que nos planteemos los problemas referentes a la educación moral del hombre. Una educación que se preocupe por la formación y desarrollo de la integridad personal, como es el caso de nuestro autor, no puede prescindir de una de sus dimensiones fundamentales, la moral. No puede entenderse una educación que descuide un ámbito humano tan importante, cuyo primer objetivo debe ser la construcción del hombre en cuanto tal, como fin en sí mismo.

Todas las teorías morales, en mayor o menor grado, están de acuerdo en afirmar que lo moral es la forma de conducta a través de la cual se expresa el rasgo más característico de lo humano, el ser más propio de la persona. Ahora bien, en la actualidad, en la postmodernidad, ¿podemos decir que la fase moral de la cultura occidental ha terminado? $Y$, en caso de que no haya terminado, iinteresa la educación moral? Incluso, concretando un poco más, ¿qué y cómo debe ser tal educación? A la primera cuestión, nos dice el profesor Aranguren, que si entendemos la moral como un rígido código de deberes; o como un ascético sometimiento extramundano de vida claustral (Edad Media), o intramundano del vivir para trabajar y de centralidad de la virtud de la laboriosidad y el trabajo (Modernidad), entonces no cabe la menor duda que la fase moral de la cultura occidental ha terminado. Sin embargo, existen otros modos, modernos o postmodernos, de entender lo moral: "Hace decenios se hablaba mucho de "concepción(es) del mundo" o "Cosmovisión(es)" que, en el mapa de las actividades del espiritu, eran situadas entre la religión o sus sucedáneos, principalmente las ideologías, y la metafisica o pseudometafísica. Mas el núcleo central de esas visiones, aparentemente de la totalidad de la realidad, era, en verdad, una concepción de la existencia, de la vida. Abora bien, eso es justamente [...] doblemente, lo que boy, con plena vigencia de un concepto nada superado sino al contrario, se entiende por moral: por una parte, el sentido que se da a la existencia en su globalidad, es decir, lo que podemos llamar macromoral $o$, con la denominación de una obra de tradicional atribución aristotélica, "gran Moral" o magna moralla; $y$, por otra parte, el "sentido" que otorgamos a los actos de nuestra vida, el "modelo" de existencia y el "estilo" de vivirla, en cuanto inscritos en la cotidianidad misma, esto es, lo que cabe denominar micromoral $o$, tomando de Adorno la expresión, mínima moralia. Si, como yo pienso, la moral

2. Ética, Madrid, Alianza, 1979.

3. "Negación del problema de la malidad. Determinismo, amoralismo, relativismo", en Propuestas morales, Madrid, Tecnos, 1983, pp. 31 a 36. 
boy, en una ampliación de su idea, ba extendido ésta a áreas de pensamiento que antes se atribuían a la filosofía teorética, porque se ha comprendido que, en filosofía lo mismo que en lingüística, la pragmática se inscribe en el centro mismo de su interés, entonces no bay duda de que la moral no ba terminado, sino que, al contrario, difuminada su antigua y precisa, rigida identidad, se ba situado en el centro mismo de la reflexión bumana ${ }^{4}$. A nuestra época, nos dice Aranguren, le falta, en todo caso, interés por la teorización moral, ahora bien, lo que no le falta es el impulso ético, el aliento morals.

En cuanto a la segunda cuestión Aranguren es tajante: "Nietzsche ba escrito que la moral es aburrida. Lo es, sin duda, la moral concebida como un código de obligaciones; lo es, doblemente, la filosofía moral que déduce cuasi matemáticamente esa tabla de deberes (Otras ciencias podrán ser más difíciles y más abstrusas que ella; más aburridas sospecho que no) (...] No, la moral no es aburrida, sino todo lo contrario. La moral, es decir, el sentido de la vida, es lo más apasionante en que el hombre puede pensar [...] Me parece que la solución está, aparte de la implicación del estudiante en la tarea moral, en la atención a la realidad, es decir, a la experiencia, a la vida, a la bistoria, a la religión [...] De todo ello y no de abstracciones tiene que alimentarse la Etica, ${ }^{6}$. La enseñanza de la ética, la educación moral, nos dice Aranguren, debe ser presentada de manera amena y agradable a los ojos del estudiante, sin perder con ello, en ningún momento, rigor. Ese es el verdadero problema de una buena educación moral. Sin embargo, los problemas no se acaban aquí, ya que el actual pluralismo y la consiguiente crisis mal que padecemos no nos permite saber cuál debe ser el modelo moral que debe transmitirse en dicha educación moral. No se trata, entiende Aranguren, de que no se deba impartir una educación moral, ésta es irrenunciable, no obstante, andamos a tientas, no disponemos de una tabla de valores y no se les puede transmitir valores pasados, por ejemplo, los propios de la modernidad, cuando éstos ya no son válidos para la postmodernidad: "[...] No renunciaremos a la educación moral de los niños, pero ésta ba de tener un sentido que todavía no podemos saber. No disponemos de una tabla de valores válida, y no les podemos proponer unos valores fijos y determinados [...],7. La moral, la educación moral, la ética, se encuentra en

4. "Nuevos enfoques de la moralidad", en Ibidem, pp. 115 y 116. La diferenciación que establece Aranguren entre magnamoral y minimamoral es la distinción entre lo bueno y lo justo, entre las invitaciones a la felicidad y las exigencias de justicia.

5. "l...] continúo creyendo que no bemos salido de la 'crisis actual de la moral', es decir, de su fundamentación teórica suficiente, frente al radical pluralismo moral de nuestro tiempo. He aqui la razón por la cual, abora lo veo, en vez de escribir un Prólogo, lo que estoy baciendo es remitir a mi bibliografía $y$, a través de ella, a mi autobiografía intelectual de moralista inserto en una situación general de crisis. No es, pues, tanto que me falten ánimos a mí —pese a los años, los conservo-como que faltan a mi época. Lo que tampoco es exacto: lo que falta a la época es el seco interés por la teorización moral, pero no - esperémoslo, y yo lo espero cada vez más- el impulso ético, el aliento moral.. "Prólogo de 1983", en Ibídem, pp. 18.

6. "La enseñanza de la Ética", en Ética de la felicidad y otros lenguajes, Madrid, Tecnos, 1988, pp. 27 a 29 .

7. Ver "Taula rodona", en Els infants, nou esclat social, Barcelona, Edimurtra, 1989, pp. 149 a 165. Ver en concreto, pp. 153. 
un tiempo de espera, en un tiempo incierto, crítico y problemático, pluralista y comprometido en un clarísimo proceso de secularización. La única forma de salir del impasse, nos dice el profesor Aranguren, es conservar el carácter prescriptivo de la ética a un nivel puramente formal. Así pues, la educación moral es necesaria, lo que sucede es que ya no puede, no debe ser presentada como un rígido código normativo al que atenerse inmutablemente, sino que hay que hacerla interesante y atenta a los constantes cambios que se producen en la sociedad.

Por último, respecto a la tercera cuestión, la educación moral no puede ser mera educación psicologista o intelectualista y tampoco simple educación social o sociológica, aunque tampoco se situará en frente de ellas, al contrario, a su lado, abriéndose a sus aportaciones que no son pocas ${ }^{8}$. Por ello precisamente, la educación moral en Aranguren no puede ser mera educación individual, sino también social, es decir, cívica y política. La educación moral debe dirigirse al desarrollo de lo más importante en el ser humano, al desarrollo de su personalidad, de su carácter moral y éste no se cierra en sí mismo, sino que se abre a los demás y se concretiza en lo que Aranguren llama democracia como moral. Por otro lado, la educación moral deberá ser normativa en cuanto a los principios morales, pero prudencial en cuanto su aplicación concreta, atenta a la situación circunstancial de cada cual: "La Ética ba sido entendida, a lo largo de toda su bistoria, hasta los tiempos presentes, como ética normativa, es decir, como la disciplina filosófica que nos dice, en el orden de los principios - no en el de los actos o el comportamiento singulares, de cada uno de nosotros, lo que es misión de la prudencia o, si se admite, de la casuistica-, lo que es bueno y lo que es malo, en general, como comportamiento; o, dicho de otro modo, lo que bemos de bacer y lo que debemos dejar de bacer [...] Nosotros vamos a seguir aquí la concepción tradicional de la Ética como disciplina normativa, entre otras razones porque así es como lo entienden todos los no-filósofos y basta los lógicos de la moral cuando se comportan no como filósofos, sino como bombres que tienen que tomar decisiones y darse a si mismos un modo coherente de vida"?. Una ética normativa entendida de esta manera implica: 1) que si bien la persona está naturalmente predispuesta a la moralidad (premoralidad/talante, moralidad/hábito/virtud, radicalidad moral/moral como estructura), debe aprender a derivar de los principios generales (normatividad) principios concretos y aplicarlos a las acciones concretas (prudencialidad); y 2) es preciso poner las condiciones para que el educando realice actos morales hasta alcanzar el hábito de obrar moralmente bien. No basta con conocer el bien, hay que ejecutarlo. La educación moral que nos va a proponer Aranguren no consistirá en dictarnos lo que hemos de hacer, sino en ayudarnos en ese hacer orientándonos en medio de las prescripciones del código moral bajo cuya vigencia vivimos, de las formas de vida que constituyen el repertorio disponible en nuestra sociedad, y de los principios o criterios en que se basa todo el sistema moral ${ }^{10}$.

8. "La enseñanza de la ética", en Ética de la felicidad y..., op. cit., p. 21.

9. Propuestas morales, op. cit., pp. 24 y 25

10. Ibidem, p. 87. 
Así pues, para Aranguren la realización moral de los hombres ha de tener en cuenta al menos tres acepciones de lo moral: 1) Lo moral ha de entenderse como la formación del carácter individual, que lleva a los individuos a adoptar ante la vida un estado de ánimo determinado (moral personal, ética individual). 2) La moral tiene una dimensión comunitaria, en la medida en que un individuo se socializa y aprende a vivir unos valores en el ámbito de una comunidad, que se nutre culturalmente de un entrecruzamiento de tradiciones. Los valores y normas de las respectivas tradiciones cristalizan en costumbres, normas legales, e instituciones, que componen el êthos de las comunidades (moral social, ética de la aliedad). 3) No obstante, quien se limite a vivir una solidaridad grupal no puede llegar a vivir democráticamente porque una auténtica democracia precisa de la solidaridad universalista de quienes, a la hora de tomar decisiones comunes, son capaces de ponerse crítica y solidariamente en el lugar de cualquier otro. Así pues, una educación integral tiene que tener en cuenta la dimensión comunitaria de la persona, su proyecto personal y vocacional, su capacidad de universalización sistémica y su capacidad de autocrítica y de crítica a los principios (humanismo, moral como actitud, ética actitudinal).

Por otra parte, siguiendo a Adela Cortina sabemos que se dan tres tipos de ética: religiosa, laicista y laica. Ética religiosa es la que apela a Dios expresamente para orientar nuestro hacer personal y comunitario. Ética laicista es la que considera imprescindible, para la realización de los hombres, eliminar de su vida el referente religioso, negar la religión, porque ésta no puede ser otra cosa que fuente de discriminación y de degradación moral. Ética laica es aquélla que no hace ninguna referencia explícita a Dios, ni para tomar su palabra como orientación, ni para rechazarla. La ética laica, como la ética cívica, puede perfectamente articularse con éticas religiosas en sociedades pluralistas. La ética laica reconoce que en la realización de las personas hay unos mínimos que compartimos y unos máximos de felicidad que ella no puede ofrecer. Se trata de unos mínimos de justicia que la moral civil exige (los derechos humanos, los valores de libertad, igualdad y solidaridad, la actitud dialógica) y unos máximos de felicidad en los que ella no se compromete, porque las ofertas de felicidad son negocio de los distintos grupos. La ética arangureniana, plenamente abierta a la religiosidad, tiene perfecta cabida dentro de los límites de una ética laica o cívica. Veámoslo con más detenimiento.

\section{LOS DISTINTOS MODELOS DE EDUCACIÓN MORAL: CRÍTICA ARANGURENIANA}

La permanencia de lo moral a lo largo de la historia presenta, a groso modo, tres grandes líneas de actuación de las cuales se desprenden distintos modelos morales y educacionales. Veámoslas brevemente para poder entresacar las diferencias fundamentales de la propuesta arangureniana.

1. En la primera línea de pensamiento podemos insertar la concepción ética fundamentadora de la moral que entiende como tales aquellas acciones que conducen a la persona a la felicidad. Son morales teleológicas porque las acciones, en cuanto a su bondad o maldad, siempre referencian a un fin, la felicidad. La tarea moral consiste en hallar los medios más adecuados para lograr el fin, al que la persona tiende por naturaleza y que, por ello, constituye su bien. Nuestro autor 
se englobaría en esta línea, es decir, sería teleológica, encaminada a la perfección moral, tendente a la configuración del carácter moral. He dicho teleológica, sin embargo, hay que matizarlo. Es teleológica en el sentido que persigue la perfección moral y ésta se encuentra en el desarrollo de la personalidad moral, sin embargo, como bien nos dice Aranguren, "[...] la moral teleológica, opuesta a la deontológica, es también insatisfactoria: el bien no puede convertirse en fin, en meta; la orientación propositiva de la vida moral linda con el racionalismo farisaico. La auténtica bondad es espontánea, cálida, surge en las situaciones concretas y, en el límite, es una gracia [...,.11. La moral arangureniana lo es del desarrollo de la personalidad moral, de la configuración del carácter o segunda naturaleza, por apropiación inteligente de la mejor forma de vida o, si se quiere, de las virtudes $^{12}$, es decir, una moral actitudinal, la única, según el profesor Aranguren, capaz de alumbrar respuestas morales.

2. Para Kant la pervivencia de lo moral tiene su raíz en la conciencia moral. La moral, nos dice Aranguren, desde Kant ha sido concebida, fundamentalmente, como moral del deber ${ }^{13}$. Los kantianos consideran un hecho real que el hombre se siente responsable de sus actos y tiene conciencia de su deber; y cree que el hecho, la moralidad, exige plantear la siguiente cuestión: ¿en qué estriba la bondad de los actos o en qué consiste lo bueno? Para Kant, lo único bueno en sí mismo es la buena voluntad. Ésta, como razón práctica pura, es la sede exclusiva y excluyente de la moralidad, de la bondad, lo único bueno sin limitación, lo único moralmente bueno ${ }^{14}$. Para la ética del deber, ni la felicidad individual, ni la felicidad social, bienes subjetivos del hombre, pueden anteponerse al respeto y la promoción de la persona. La buena voluntad es la que actúa por puro respeto al deber, sin razones distintas del cumplimiento del deber, de la sujeción a la ley moral. El deber que ha de ser cumplido es incondicionado y absoluto. Lo que la buena voluntad ordena es universal por su forma, independientemente del conte-

11. "Filosofías racionalistas, filosofías no éticas y Kant”, en Guıś́n, E. (Ed.): Esplendor y miseria de la ética kantiana, Barcelona, Anthropos, 1988, pp. 23 a 28.

12. Alasdair McIntyre intenta rehabilitar hoy en dia la moral de las virtudes, porque entiende, acertadamente, que la modernidad ha incidido en exceso en la importancia de los deberes y las normas para la moral y ha descuidado el papel de las virtudes. Ver McInTYre, A.: Tras la virtud, Barcelona, Crítica, 1987.

13. "Kant fue el autor que llevó a esta revolución copernicana de la moral, paralela de la que bizo en la teoria del conocimiento. Para ello se apoyó en una posibilidad que le brindaba su lengua: la de distinguir entre Gut $y$ Wohl (asi como entre Böse $y$ Schlecht) acotando la significación de las primeras palabras para el bien ( $y$ el mal) moral y asignando las segundas al bien (y el mal) de carácter no moral. Asi, las cosas que llamamos buenas lo son en el sentido de Wohl. Pero lo único que merece ser llamado bueno no está fuera de nosotros, sino en nosotros mismos; ni puede ser la felicidad, puesto que, en cuanto tendemos a ella necesariamente, por inclinación natural, no tiene nada que ver con la moral; sino que es, exclusivamente, la buena voluntad, atenida al deber. Propuestas morales, op. cit., p. 56.

14. "Nada más, ni dentro del hombre (inclinación, etc.), ni fuera de él, en la realidad exterior. La separación kantiana es radical entre el orden del estar o ser (y del llegar a ser o estar) y el orden del deber. El primero está rigurosamente sometido a la causalidad natural o real y es totalmente ajeno a la moral; el segundo, 'irrealmente' liberado de ella, no es un reino de este mundo, está separado de él. "Filosofias racionalistas, filosofías no éticas y Kant", en GUISÁn, E. (Ed.): Esplendor y miseria de la ética kantiana, op. cit., p. 27. 
nido concreto que se le dé. Dicho en otras palabras, la ética de Kant es rigurosamente individualista y consistente en una apelación a la conciencia de cada cual, para que cumpla con su deber. Además, lo que manda la buena voluntad se refiere a todos los hombres, en todos los tiempos y en cualquier circunstancia, es decir, además de individualista, es universalista y descontextualizada. Esto es lo que Kant llama el imperativo categórico: obrar de tal forma que lo que uno haga, por su moralidad, pueda ser motivo de ley universal. La moral kantiana, por lo tanto, implica que dicha moral no tiene un referente distinto al hombre y no es una moral de contenidos concretos. Es, por lo tanto, una moral formal (sirve para todos los hombres, contenidos y circunstancias) y autónoma (porque surge de la razón práctica del propio sujeto y de una voluntad libre, activa y creadora). Kant, por lo tanto, estableció, en cierto sentido, un reduccionismo, el de reducir lo moralmente bueno al cumplimiento del deber. Ésta es una de las objeciones que Aranguren hace a la teoría moral kantiana: "...J Reduccionismo que no todos, ni mucho menos, estamos dispuestos a admitir, pues es patente que muchas acciones sería bueno que se llevasen a cabo, aún cuando de ningún modo puede decirse que constituyen deber. El deber es, por decirlo asî, la cara negativa, coercitiva, obligatoria del bien morabis.

Otra crítica es el excesivo racionalismo kantiano. El racionalismo moral, nos dice Aranguren, consiste en afirmar que la única causalidad moral es la de la razón ${ }^{16}$. Kant rechaza el sentimiento, la inclinación, la virtud. No obstante, la inclinación, el sentimiento, la pasión, la actitud y la virtud, sigue diciéndonos el profesor Aranguren, constituyen la fuerza moral. La razón esclarece al sentimiento y lo eleva a la verdad. Paralelamente y al mismo tiempo, el sentimiento mueve a la razón: “[...J la pre-ferencia sólo puede ejercitarse sobre las ferencias, las incilinaciones que nos llevarian de acá para allá. En definitiva, Kant queda prisionero de una psicología de facultades separadas, que bipostasia, para mal, al sentimiento, y para bien, a la razón ${ }^{17}$. Así, por ejemplo, sigue diciéndonos el profesor Aranguren, "[...] La inclinación, esa simpatía profunda que se tienen las madres y los hijos, o la que se tienen personas del mismo y de distinto sexo, eso es la inclinación. Entonces dice Kant: 'si yo soy bueno por inclinación, porque esta chica me tiene loco y soy capaz de hacer por ella lo que sea, entonces no soy bueno; eso no tiene ningún mérito, no, tengo que bacerlo por deber, de una manera absolutamente fría y dejando a un lado la inclinación. Si entonces me comporto con esa chica igual que con este señor por el que no tengo ninguna inclinación ni simpatía, entonces es cuando me comporto verdaderamente bien desde un punto de vista moral. Lo que se hace por inclinación, no es moral',18.

Ahora bien, pese a esta crítica, nuestro autor no está abogando por una filosofía emocional, por una filosofía patética que pronto deja de ser filosofía. No,

15 Propuestas morales, op. cit., p. 57.

16 "Fisolosías racionalistas, filosofías no éticas y Kant", en GuISÁN, E. (Ed.): Esplendor y miseria de la ética kantiana, op. cit., p. 27.

17. Ibidem

18. "Ética y comunidades adultas", en Ética de la felicidad y..., op. cit., p. 145. 
evidentemente. Lo que sucede es que entre la ratio y el pathos, entre el deber y el ser hay, nos dice Aranguren, un tertiumquid, un punto intermedio de equilibrio al que se debería tender. La ética, la educación moral, como ya hemos visto, debe ser una guía, una orientación en el quehacer diario. Esta ayuda debe ser, según Aranguren, eminentemente racional: "Es justamente desde el punto de vista de la razón como ella nos enseña a examinar los preceptos y propuestas de la moral en uso 19 . Sin embargo, su función no debe ser únicamente negativa, sino también positiva, debe dar razones para la producción de decisiones, la modificación de sentimientos y la elaboración de un comportamiento moral.

A estas dos críticas hay que añadir que: 1) Frente al individualismo ético kantiano, Aranguren propone que el êthos personal debe abrirse al êthos social. 2) Al rechazo que Kant hace de la metafísica clásica, Aranguren propone que la ética esté subordinada a la metafísica. 3) A la dependencia de la religión respecto de la moral que establece Kant, Aranguren propone una ética que necesita abrirse a la religión. 4) Al formalismo ético kantiano, Aranguren nos dice que la ética necesita necesariamente contenidos morales. Sin embargo, Aranguren nos recuerda que la ética kantiana, por existencias metodológicas, no podía presentarse como material, aunque y a pesar del deísmo reinante y de la crisis incipiente del cristianismo, admitía, sin confesarlo, la moral cristiana vigente: "Cuando Kant acepta como punto de partida el factum de la moralidad, lo que acepta, sin hacerse siquiera cuestión de ello, por su abistoricismo filosófico, es la moral cristiana protestante, 20. Consecuentemente podemos pensar con Aranguren, que si el primer formalismo ético de la historia admitía el contenido cristiano, cualquier formalismo ético posterior difícilmente podrá ser puro, se situará, consciente o inconscientemente, en un sistema ético de donde extraerá sus contenidos morales. Aranguren, por lo tanto, no sólo critica el formalismo kantiano, sino que nos hace ver que todo formalismo ético es más nominal que real ${ }^{21}$.

3. La tercera línea de actuación, de plena vigencia en la actualidad, es la ética discursiva que tiene su corolario en la educación moral para el desarrollo del juicio moral. Aranguren, con un lenguaje preciso y crítico, nos sintetiza perfectamente sus notas dominantes: "I... J sobriedad, rigor $y$, en el plural sentido de la palabra, 'formalidad', dentro de una 'época de "neos" explicitos o implicitos' [...] Época de tendencia a la 'reducción de la ética a un capitulo de la filosofía del derecho' [...]; época de 'ética fragmentaria' [...] normativa, si, pero 'poco', 'de minimos' o minimalista, fundamentadora de una moral que se conforma con el consenso fáctico para la pragmática solución de los conflictos. Y que, cuando se decide a levantar el vuelo, se dice 'ética que no es de este mundo', que demanda - sin ganas, claro- el sacrificio de la propia alma a la 'comunidad ilimitada', a la laica e irreal 'comunión de los santos' [...], época de [...] 'razón sin esperanza', de 'desmoralización' en el doble sentido de la palabra [...]; en fin, de una razón neoilustrada, y

19. "Decisión por razonamiento y decisión por persuasión", en Propuestas morales, op. cit., pp. 87.

20. "La ética protestante", en CAMPS, V. (Ed.): Historia de la ética 1. De los griegos al Renacimiento, Barcelona, Crítica, 1988, p. 498.

21. Ibidem, pp. 490 a 506. 
no sólo en tanto que pura razón, fría y desvitalizada, sino también en tanto que reduccionista, positiva y meramente procedimental, 22 .

Efectivamente, en la actualidad el hecho moral por excelencia, del que muchos parten para justificar la dimensión moral de la persona, es la existencia de un determinado lenguaje moral encaminado a la incesante búsqueda de lo consensual. Aranguren nos dice al respecto que la ética es discurso moral23 porque, efectivamente, para esta línea de pensamiento, existen modos de expresar términos, juicios y argumentos claramente morales, es decir, existe un determinado lenguaje moral ${ }^{24}$. Tal lenguaje posee un sentido y es perfectamente defendible desde el momento en que nos damos cuenta de que sus términos son usados cumpliendo una función en beneficio de sus usuarios. El lenguaje moral viene respaldado, y con ello cobra sentido, por una forma de vida que lo sustenta (estilo de vida, actitud coherente, educación moral testimonial). El lenguaje moral puede poseer diferentes interpretaciones, porque, indudablemente, se inserta dentro de la estructura unitaria del hombre y éste es básicamente ambiguo. En función de esta ambigüedad unas personas puede que lo entiendan en su sentido y le confieran un uso, y otras personas lo comprendan y usen con un sentido diferente o incluso radicalmente opuesto. También es posible que las personas actúen inmoralmente pero los términos morales, de alguna manera, son comprendidos y usados porque, efectivamente, existe un lenguaje moral: "[...] el hombre se ha dado a sí mismo un lenguaje moral [...que] es irreductible a cualquier otro,25.

En este plano hay que colocar las éticas dialógicas, discursivas o comunicativas que, teniendo su antecedente en la ética kantiana y, por lo tanto, ser también éticas deontológicas o del deber, consideran que los juicios morales pueden solventar los problemas y conflictos de acción sobre la base de un acuerdo racionalmente motivado, justificando para ello las acciones en función de normas válidas, y la validez de las normas a la luz de principios dignos de ser reconocidos. La rectitud de la norma, por lo tanto, es una pretensión de validez análoga a la veracidad. Ciertamente, a comienzos de los años setenta, en el ámbito de la filosofía, aparece una nueva propuesta ética: la teoría de la acción comunicativa. Las éticas comunicativas descubren el carácter intersubjetivo y dialógico de la formación de la conciencia moral. Consideran que las normas morales pueden y deben ser argumentadas, y que es deseable que la argumentación tenga un valor universal, dado que con frecuencia los problemas son colectivos. No bastaría, por lo tanto, con una validez únicamente individual, sino que las normas deberían servir y ser compartidas por todos los implicados en un conflicto moral. Estas propuestas son evidentemente, neokantianas, en el sentido de que su origen están en las posiciones defendidas por Kant, sin embargo, la aportación de éste sufre modificaciones importantes: en la

22. "Prólogo", en CoRTINA, A.: Ética mínima. Introducción a la filosofía práctica, Madrid, Tecnos, 1986, pp. 11 y 12. p. 88.

23. "Decisión por razonamiento y decisión por persuasión", en Propuestas morales, op. cit.,

24. "Ética del lenguaje", en Moralidades de boy y de mañana, Madird, Taurus, 1973, pp. 129 y 130.

25. "El hombre, estructuralmente moral", en Propuestas morales, op. cit., p. 86. 
teoría de la acción comunicativa el concepto de persona defendido por Kant, que insistía en el valor de la conciencia individual, se transforma en la idea de persona como ser dotado de capacidad comunicativa, a quien nadie puede privar de su derecho a defender sus pretensiones racionales mediante el diálogo. La ética comunicativa entiende que las cuestiones prácticas pueden ser decididas racionalmente.

Nos encontramos, por lo tanto, con una ética: 1) Formal, sin contenidos, propone como principio moral el diálogo y el consenso, es decir, la validez fundamentada en el asentimiento de todos los afectados como participantes de un discurso práctico, fruto del diálogo a un mismo nivel de participación. No determina normas concretas de conducta ni tampoco indica la manera de aplicar los principios formales y abstractos en cada realidad histórica concreta, ya que lo considera contenido no susceptible de universalismo. 2) Cognitivista, ya que considera que los juicios morales tienen un contenido racional que permite distinguir juicios morales más o menos óptimos. 3) Deontológica, porque se ocupa de la vertiente normativa del fenómeno moral y prescinde de las cuestiones referentes a la felicidad y a la vida buena. Parte de la necesidad de que exista un mínimo normativo universal para posibilitar el pluralismo de las formas de vida. No obstante ello, no pretende, en ningún momento, determinar lo que es bueno, ni tiene como objeto facilitar orientaciones sobre el contenido moral. Se trata de una ética procedimental. 4) Universalista, no se trata de un principio moral, sino de una regla argumentativa utilizada para comprobar en qué medida el principio ético se aplica de forma correcta.

He dicho que la ética es discurso moral, sin embargo, Aranguren se pregunta si es siempre y sólo discurso, acción de discurrir racionalmente sobre asuntos morales. Se trata de ver, por lo tanto, nos dice nuestro autor, 1) si la ética es sólo puro razonamiento; y 2) si siempre es razonamiento. Si nos movemos en el plano estrictamente filosófico, sigue diciéndonos Aranguren, ambos aspectos deben contestarse afirmativamente, porque la filosofía es razonamiento y no debe ser más que razonamiento. Sin embargo, el pensamiento normativo se mueve a diferentes niveles: «[... l el superior, de la ética filosófica, pero también otros de discusión, convencimiento o preparación racional de una decisión moral. Por otra parte, hay gentes que, siendo suficientemente razonables, se sienten incapaces de leer tratados de ética a palo seco. ¿Habría entonces que renunciar a bablar con ellos de moral? Tenemos ante nosotros la vieja distinción platónica de dialéctica y retórica. $Y$ frente a Platón debemos afirmar con energía que todos los hombres son capaces de entender el lenguaje de la dialéctica (al menos potencialmente capaces, y nosotros, la sociedad, el Estado, tenemos la obligación de actualizar esa potencia) y dignos de que se les hable en él. Pero ¿en qué lenguaje de la pura dialéctica, sin concesión, sin ilustración, sin metáfora alguna? ¿Es irracional, es inmoral presentar el discurso ético en forma atractiva, artística, figurativa, para que sea capaz de mover al lector y oyente en todo su ser, no contentándose con bablar secamente a su razón?,26. Siempre que no se sacrifique el rigor, la educación moral, la ética, debe presentarse de manera interesante, es decir, no necesita ser siempre puramente racional: "Impedir el aburrimiento, suscitar interés, escribir brillantemente,

26. "Decisión por razonamiento y decisión por persuasión", en Ibidem, p. 87. 
da a la dimensión emotiva su parte legitima, siempre que con ello no se sacrifique el rigor del razonamiento, que sirve al bello discurso de sólida armazón. El discurso moral no necesita ser siempre puro razonamiento 27 . Ahora bien, el discurso moral debe ser siempre racional. La dimensión emotiva no puede prevalecer sobre la cognitiva, porque entonces salimos ya del ámbito del razonamiento para entrar en el de la persuasión: "El lenguaje que no se propone convencer, sino persuadir disparando los impulsos, las tendencias, los oscuros sentimientos o las violentas emociones, es ya inmoral, cualquiera que sea el fin que se proponga conseguir, e incluso si ese fin fuese bueno. El bombre es acreedor a que se le trate como fin en si mismo, no como medio manipulable tocando sus resortes emocionales $y$, a veces, ni siquiera eso, accionando lo que su psiquismo tiene de inertemente mecánico (persuasión por mera repetición).28. En definitiva, Aranguren no puede sostener la radical separación que se da en este enfoque ético entre el sentimiento y la razón 29.

Por otra parte, el acuerdo moral sólo puede proceder del consenso racional y libre, de la sustitución de cualquier clase de heteronomía o imposición por el lenguaje y el diálogo. El supuesto de una ética, de una educación moral dialógica o dialogal, nos dice Aranguren, no es "L...] la tolerancia, la condescendencia o la transigencia, que son demasiado poco. Tolerancia, de tolerare, es soportar, ser paciente, consentir... el mal (por evitar males mayores); condescendencia, es descender a un nivel moral inferior; transigencia, ceder del propio derecho para facilitar la convivencia. En el plano de la moral cívica no se trata de nada de eso. Su punto de partida es el respeto al valor moral de la persona, a la dignidad del otro. No un valor friamente reconocido, sino por el que debo ser afectado en la doble acepción de sentir afecto moral por el otro en tanto que otro, y de sentirme afectado por lo que dice, por su punto de vista, por su parte de razón morab,30. Ahora bien, para Aranguren este consenso no deja de situarse en un cierto plano de idealidad. La situación ideal de diálogo nos conduciría, sin más, a la coincidencia. Las cosas no son así en la realidad. La moral dialógica no es una moral situada, no se da en la realidad y, por ello, no se puede fundar sobre ella ningún consenso. Ahora bien, tal consenso sí se podría lograr sobre el reconocimiento, nos dice el profe-

\section{Ibidem, p. 89 .}

28. Ibidem, pp. 89 y 90. Éste es el intento kantiano, que comparte Aranguren, de fundamentar en la razón el hecho de que toda persona es un fin en sí misma y no un simple medio, de que todo ser racional posee un valor absoluto y no se le puede utilizar para satisfacer preferencias individuales y grupales.

29. BRANDT, R. B.: Teoría ética, Alianza, Madrid, 1982, intenta superar esta problemática y presenta la razón como elemento que ayuda a tomar decisiones, y la afectividad (actitud, intereses, deseos, etc.), como ámbito que es reconducido por la razón. La necesidad de reconocer el elemento emotivo en los juicios éticos, así como la necesidad de disponer de un método para utilizar unos principios que equilibren la visión subjetiva de los hechos, son puntos básicos de dicha teoría. Por su parte, Hare, R. M.: Moral Thinking, Oxford, OUP, 1981, defiende los supuestos de emotividad y prescriptividad y se afirma que la función de la ética consiste en unir y equilibrar las diferentes actitudes e intereses con principios imparciales. Estos principios o preferencias tendrían el carácter de universales y no consistirían en intereses individuales armonizados, sino en intereses nacidos de la interacción con los intereses de los demás. 
sor Aranguren, de que, a excepción de la buena voluntad, ".... en este mundo no bay nada bueno sin limitación y de que, por consiguiente, toda afirmación moral es bifronte, bivalente, ambivalente, es afirmación, cuando menos, parcial, de un algo que no es todo, de una luz que va acompañada de su propia sombra. Y el otro lado de la afirmación, lo que tiene, indefectiblemente, de negación de lo que no es ella misma, de negación de su contrapunto, es lo que el punto de vista del otro aporta y lo que me debe afectar. Respeto, pues, moral al otro, por el valor en si de su dignidad personal, pero respeto intelectual también, por la aportación moral que su punto de vista puede suponem 31 . Dicho en otras palabras, junto al consenso (no frente a él), Aranguren resalta la importancia del disenso.

La gran limitación de la ética comunicativa, para nuestro autor, es la insensibilidad para el valor moral del disenso, de la cuestionabilidad, la antinomia, la contradicción, la asimetría ${ }^{32}$. Los conflictos reales, como nos dice Muguerza ${ }^{33}$, rara vez se resuelven por medio de consensos ideales y no siempre podemos resolverlos mediante los que no lo son, lo que aquellas situaciones conflictivas contribuyen a poner de relieve es la nada desdeñable importancia del disenso de los individuos para la vida democrática y, aunque por lo general no sea reconocido de esta forma, también para la ética comunicativa que pretende fundamentarla filosóficamente. La disensión es siempre individual y nace de una decisión tomada en solitario, por más que pueda serlo solidariamente, desde el interior de la conciencia disidente, una decisión intrasubjetiva para distinguirla de la intersubjetiva: "[...] ¿No gustan estos filósofos, desde Heidegger a Apel, de decir, repitiendo a Hölderlin, que somos un diálogo? Cada uno de nosotros lo es. Junto a la ética intersubjetiva, debe hacerse un lugar a la ética intrasubjetiva, al diálogo en que cada uno de nosotros consistimos,34. De ahí, precisamente, la importancia de la virtud prudencial. Los principios y normas a los que se refieren las éticas dialógicas no indican normas de actuación, ni enjuiciamiento concreto y no sirven de modo inmediato para resolver los conflictos de valor con que los sujetos se encuentran cotidianamente. Se observa, por lo tanto, la necesidad de crear normas morales contextualizadas y referidas a las condiciones de vida reales de las distintas comunidades e individuos, o sea, la necesidad de traducir la metanorma moral a normas

30. "La situación de los valores morales hoy", en Propuestas morales, op. cit., pp. 131 y 132.

31. "Decisión por razonamientoy decisión por persuasión", en Ibidem, p. 32.

32. "Ética comunicativa y democracia", en APEL, K. O.; CortinA, A.; De ZAN, J. y Michelini, D. (Edits.): Ética comunicativa y democracia, Barcelona, Crítica, 1991, pp. 209 a 218, concretamente, pp. 214 y 215.

31. "Decisión por razonamiento y decisión por persuasión", en Ibidem, p. 132.

32. "Ética comunicativa y democracia", en Apel, K. O.; Cortina, A.; De ZAN, J. y Mrchelin, D. (Edits.): Etica comunicativa y democracia, Barcelona, Crítica, 1991, pp. 209-218, concretamente, pp. 214 y 215.

33. Muguerza, J.: "¿Una nueva aventura del Barón de Münchhausen? (Visita a la "comunidad de comunicación" de Karl-Otto Apel)", en Ibidem, pp. 132 a 163. Ver en cocnreto pp. 1611163.

34. "Prólogo", en CoRTina, A.: Ética minima. Introducción a la filosofía práctica, op. cit., p. 15.

35. Ver Gadamer, H. G.: "Sobre la posibilidad de una Ética filosófica", en Gadamer, H. G.: El arte de comprender, escritos II, París, Aubier, 1991, pp. 311 a 328; Verdad y método, Salamanca, Sígueme, 1988; y El problema de la conciencia bistórica, Madrid, Tecnos, 1993. 
morales concretas y situadas en el contexto histórico-social35. De ahí, precisamente, la importancia que Aranguren concede a la virtud de la prudencia ${ }^{36}$. No olvidemos que para el profesor Aranguren la educación moral deberá ser normativa en cuanto a los principios morales, pero prudencial en cuanto a su aplicación concreta.

\section{LA EDUCACIÓN MORAL: PROPUESTA ARANGURENIANA}

Todas estas concepciones que hemos visto desembocan en el gran pluralismo moral existente en nuestra sociedad. La tarea a nuestro alcance, nos dice Aranguren, es, teoréticamente, lograr la comunicación entre los supuestos de las diferentes morales y, desde el punto de vista de la praxis, mantener la solidaridad, principio fundamental de toda moral. Creo que estas palabras son sobradamente clarificadoras del carácter abierto, dialogante y heterodoxo de nuestro autor, alejado de cualquier absolutismo u ortodoxia. Todo lo dicho hasta ahora, traducido al plano de la educación moral, una educación moral, no lo olvidemos, normativa en el seno de una sociedad secular, pluralista y cambiante, desembocaría en una educación de carácter actitudinal y prudencial porque el objeto propio de la reflexión moral es el êthos, el carácter o personalidad moral formada en la vida por la apropiación de posibilidades, a través de los buenos hábitos, de las virtudes adquiridas voluntaria y racionalmente. Ahora bien, la personalidad moral es unitaria e indisociable y por ello la educación moral arangureniana deberá ser educación moral, cívica y política. En este artículo nos vamos a limitar a la educación moral personal, dejando la cívico-política, para otro artículo.

La personalidad moral es un concepto netamente moral que Aranguren distingue muy claramente del concepto premoral, talante o páthos. El talante es la forma natural que el hombre tiene para habérselas con la vida. El talante, como forma natural, nos viene dado, no depende, en ningún caso, de nosotros, sino que son nuestras estructuras psicobiológicas, nuestra naturaleza, quien nos lo proporciona. El talante, sin embargo y pese a ello, es fundamental para construir la personalidad moral. El talante es la realidad antropológica en la que nos encontramos, con la que convivimos, y con la que es preciso contar a la hora de proyectar, de valorar, de decidir, de elegir, de actuar, de hacer, en definitiva, nuestro particular modo de ser, nuestro êthos o carácter moral. El talante es, por lo tanto, qué duda cabe, la fuerza que poseemos para nuestra forja, para nuestro quehacer. Contando en todo momento con el talante, con la materia prima, operando sobre ella, modificándola, encauzándola, moldeándola, iremos haciendo de manera racional y voluntaria, por medio, no de actos aislados, sino de los hábitos que vamos adquiriendo por decisión propia, nuestro êthos. La tarea moral sobre la que debe incidir la educación moral no es otra que la de llegar a ser lo que se puede ser con lo que se es. El talante, además, es la tonalidad anímica, el estado de espí-

36. "La ética protestante", en CAMPS, V. (Ed.): Historia de la ética 1. De los griegos al Renacimiento, op. cit, p. 498. 
ritu, el orden afectivo y sentimental con que nos enfrentamos por naturaleza a la vida. La importancia de los sentimientos, del plano afectivo, además de la razón, es fundamental en Aranguren.

Así pues, Aranguren considera más significativo, moralmente hablando, la personalidad moral que los actos aislados y los hábitos repetidos por costumbre. El êthos, como tarea moral que todo hombre tiene que emprender y realizar, se hace evidente desde la dimensión de la moral como estructura o, lo que es lo mismo, desde nuestra condición humana. Son las propias estructuras antropológicas del ser humano las que le obligan a realizar, a hacer su vida. La manera en que ha de hacer su vida viene marcada por el contenido moral que se haya escogido. El porqué el hombre ha de hacer su vida es una exigencia natural, antropológica, mientras que el cómo debe hacerlo vendrá marcado por los contenidos morales, por la idea del hombre que se conciba y, consecuentemente, por la escala de valores por la que se opte. El contenido concreto de la moral que en Aranguren depende en parte de la religión, será la base material sobre la que se edificará el êthos. Para Aranguren la vida no es la instancia ética decisiva, lo verdaderamente importante no es lo que pasa, sino lo que queda, es decir, no la vida, sino lo que hemos hecho con ella, el carácter que hemos ido adquiriendo en la vida haciendo cosas, en definitiva, la vida tal como queda hecha. Una vida, sin embargo, contextualizada, enmarcada en un determinado contexto socio-histórico. La personalidad moral, el êthos personal debe abrirse, necesariamente, al êthos social. La educación moral arangureniana ha de ser eminentemente práctica y enmarcada dentro de la realidad social. La relación entre el juicio moral, la decisión ética y la acción responsable, es íntima.

¿Qué objetivos debe perseguir una educación moral fundamentada en los presupuestos arangurenianos? Parece claro que el objetivo general sería el desarrollo armónico de la personalidad moral, del carácter moral, en definitiva, del êthos. Es decir, el desarrollo y fortalecimiento de la capacidad que la persona tiene de obrar en libertad y de dirigirse voluntariamente hacia su bien, hacia la buena vida, hacia su perfección a través del cumplimiento de los deberes que se le exigen, independientemente de los condicionamientos y presiones sociales que pueda tener. Dicho en otras palabras, la apropiación de un determinado estilo de vida coherente con su pensamiento moral. Por lo tanto, el objetivo último de la educación moral no sería tanto el desarrollo de formas y modelos de razonamiento, como el cultivo de una personalidad moral capaz de conductas y acciones morales. Así pues, la educación moral debería convertirse en un ámbito de reflexión personal y social, que permitiera elaborar racional y autónoma-. mente, a partir de principios generales, principios concretos que dispusieran para la acción responsable (construcción de criterios morales propios, razonados, solidarios y no sujetos a meras exigencias externas); ayudar a analizar críticamente la realidad cotidiana y las normas sociomorales vigentes, de modo que ayudase a idear formas más justas y adecuadas de convivencia; aproximar a los

37. "Los principios de la mal y la empresa de la moralización", en Propuestas morales, op. cit., pp. 74 a 76.

(c) Ediciones Universidad de Salamanca

Teor. educ. 9, 1997, pp. 75-91 
alumnos hacia conductas y hábitos más coherentes con los principios y normas particulares que hayan construidos, de forma que hubiera una clara coherencia entre la decisión prudencial y la acción moral.

Una educación moral de carácter normativo y actitudinal, fundamentada en las virtudes, debería proponerse, sobre todo, nos dice el profesor Aranguren ${ }^{37}$ :

1. Formar las capacidades y la adquisición de los conocimientos precisos que capaciten al educando para someter y revisar críticamente el/los código/s moral/es vigente/s y los principios morales sobre los que se sustenta/n, en un diálogo crítico y creativo con el entorno y su circunstancia 38 .

2. Desarrollar la inteligencia práctica, el juicio moral, la virtud prudencial, el necesario talante moral, para crear nuevas pautas de comportamiento, nuevos patrones de vida, nuevos proyectos contextualizados, que contribuyan a la creación de una existencia mejor, en lo personal y en lo social.

3. Establecer la necesaria coherencia entre la decisión prudencial y la acción moral, es decir, actuar actitudinalmente en lo que Aranguren llama moral como actitud.

4. Concienciar al alumno de que sólo él es el responsable último de las decisiones morales o inmorales que tome: responsabilidad moral personal y corresponsabilidad moral social.

¿Qué contenidos debe cumplimentar esta educación moral? Los contenidos morales que se deben desarrollar, lejos de ser una abstracción, pura formalidad, deben estar ubicados en situaciones concretas. Los contenidos de la moral surgen de la cultura, siempre en su acepción antropológico-cultural, es decir, de los modos de vida, de los estilos de comportamiento, de los patrones existenciales y también de la moral implicada en cada religión. Los valores surgen por la concepción de la vida emergente o declinante y la concepción de la vida viene determinada históricamente por la religión o por interpretaciones religiosas ${ }^{39}$, todo ello al hilo de la experiencia de la vida en el desarrollo histórico de las culturas abiertas y, por lo tanto, plurales. Los contenidos morales, consecuentemente, deben referirse a los problemas morales planteados en la actualidad y en el seno de cada comunidad: "La moral social suele dividirse, para su estudio, en moral sexual y doméstico-familiar, moral económico-laboral y moral política. Por otra parte, tradicionalmente se distinguian los niveles sociales de la familia, el municipio o vecindad, el gremio o sindicato y la societas civilis o Estado y ello, asi como la crisis actual de la familia y la que ya hemos considerado, del êthos laboral, bace pensar que debe dedicarse un apartado especial a esa peculiar "vecindad" que consti-

38. Aceptar lo establecido por convencional, aquello que la gente dice y repite que es bueno porque siempre ha estado ahí, sin someterlo a un serio examen intelectual y moral, lejos de ser moral, nos dice Aranguren, es inmoral: "Obrar conforme a normas o principios morales que aceptamos dócilmente sólo porque están vigentes en nuestro grupo social, pero sin que nosotros veamos su razón de ser, no es obrar moralmente, porque de ese modo no contribuimos a la progresiva moralización, sino que, al contrario, convertimos la moral en una realidad inerte, cosificada, muerta, que, lejos de mover a la acción creadora, pesa como una losa que empuja al individuo $y$, si esta conformista actitud se generaliza, a la comunidad entera al estado de 'sociedad cerrada'. Ibidem, p. 75.

39. "Moral religiosa", en El buen talante, Madrid, Tecnos, 1985, pp. 89 y 90. 
tuyen, en la niñez, en la adolescencia, y en la edad adulta, los compañeros, los amigos - formas viejas y nuevas de amistad - y al modo como empleamos el tiempo con ellos. La importancia que ha cobrado el tiempo libre, a expensas del tiempo laboral y, con frecuencia, del familiar; el peculiar empleo moderno del tiempo que, llamado libre, se organiza y programa tan rigurosamente como el del trabajo; $y$, en fin, los mores específicos de la vida cotidiana, su calidad y su ritmo; todo ello parece demandar una particular atención ya que [...] es bacia esa zona, en la modernidad un tanto marginada, bacia donde parece desplazarse la búsqueda contemporánea del sentido moral de la vida, ${ }^{40}$. Ahora bien, como el objeto de la ética es el êthos, carácter o personalidad moral, apropiado a través de la vida, mientras vivimos, a través de los actos y también de los hábitos que quedan incorporados en forma de virtudes al carácter moral, el conocimiento y práctica, en circunstancias concretas de la vida, de las virtudes morales debe ser un contenido básico de la educación moral: la moral debe entenderse como el hacerse del hombre a sí mismo a través de su quehacer mundano por medio de las virtudes que tienden a constituirse como centrales de la personalidad, de tal modo que sea en torno a ellas como se organice ésta ${ }^{41}$.

El hombre, nos ha dicho el profesor Aranguren, se puede definir como animal de posibilidades apropiadas. Hay una posibilidad, sin embargo, que está siempre constitutivamente apropiada, si bien problemáticamente: la felicidad. Hay luego otras muchas posibilidades apropiables: los bienes. De éstos, algunos, los deberes, son además apropiados. Y la configuración moral del hombre se lleva a cabo por sus apropiaciones cumplidas y arraigadas: virtudes y vicios. Para Aranguren, siguiendo en ello a Aristóteles, la virtud es una posesión, pero no dada por naturaleza, sino adquirida por libre elección. Esta elección se hace con arreglo a una norma, rectitud de la inteligencia que se concreta prudencialmente: la recta elección de lo que se ha de hacer, el término medio entre el exceso y el defecto, lo que viene a significar que la virtud consiste en seguir el camino recto, sin torcerse ni hacia la derecha ni hacia la izquierda, es decir, sin pecar por exceso o por defecto (rectitud) ${ }^{4}$. La virtud, además de todo lo dicho, es también fuerza moral. Las virtudes son una fuerza. Sin embargo, y esto moralmente es muy importante, cuando se mecanizan, cuando las virtudes pierden su ordenación al bien y se degradan a simples prácticas, entonces se pueden volver contra el hombre. Porque la práctica de la virtud, vaciada de su sentido, no es ya virtud, sino virtud manía, inercia, tiranía, gimnasia ética: el rigor moral por puro masoquismo, el fanatismo, el exclusivismo, nos dice el profesor Aranguren. La virtud por la virtud al modo estoico, la sofocación de ciertas virtudes por hipertrofia de otras y el automatismo de las virtudes, son algunos de los peligros que amenazan la vida moral y que una correcta educación moral debe analizar críticamente ${ }^{43}$.

40. "La moral social", en Ética de la felicidad y..., op. cit., p. 114.

41. "El oficio del moralista en la sociedad actual", en El buen talante, op. cit., pp. 49 a 62.

42. Ética, op. cit., p. 237.

43. Ibidem, pp. 239 y 240. 
Aranguren distingue entre las virtudes dianoéticas o intelectuales y las virtudes éticas o morales. Las primeras sólo deben llamarse buenas en tanto que hacen del hombre un buen filósofo o un buen artífice, pero de las que puede hacerse un uso moralmente malo, es decir, son ambivalentes. Por el contrario, las virtudes éticas nunca son ambivalentes, son simplemente buenas. Así pues, el concepto de virtud compete más a las virtudes morales que a las virtudes intelectuales. Las cuatro virtudes fundamentales son las cardinales: 1) determinación racional del bien (prudencia o inteligencia práctica); 2) institución o establecimientos del bien (justicia); 3) firmeza para adherirse a ella (fortaleza); y 4) moderación para no dejarse arrastrar a su contrario, el mal (templanza). El resto de las virtudes pueden considerarse fruto y efeto del cumplimiento de éstas en la vida social.

Sin embargo, quizá lo más importante que hay que destacar en la educación moral de Aranguren, educación basada en las virtudes como uno de los contenidos morales, es que "[...] más que la clasificación aceptada [...lo que verdaderamente importa, es... mantener la disponibilidad empirica y la capacidad critica frente a cualquier cuadro. Sin embargo, repitámoslo, muchos más que discutirlo importa no petrificarlo, mantenerlo abierto a la experiencia bistórica del descubrimiento y la realización de las diferentes virtudes posibles" 44 . Para Aranguren los temas que deben plantearse en una verdadera educación moral son 1) los problemas vivos de nuestra sociedad; y 2) las virtudes para los conflictos que tienen planteados el hombre y la sociedad, así como la actuación, incluso con un cambio de nombre si fuese necesario, de ciertas virtudes, muy necesarias y poco acreditadas (por ejemplo, la prudencia). La moralización no debe consistir en elaborar o reelaborar un perfecto cuadro de virtudes para transmitir acríticamente. Hay que reaccionar contra el sistematismo y dar vida auténtica a las virtudes, sacándolas del casillero donde un tanto rutinariamente acostumbran a ponerse, haciendo ver que, en realidad, trascienden todos los cuadros, porque, como manifestación que son de un êthos unitario, se hallan, más allá de todas las clasificaciones, estrechamente vinculadas entre sí. Por otra parte, sigue diciéndonos Aranguren, como reacción frente al refugio burgués en la virtud privada e individualista, es menester dar toda su importancia a la virtud de contenido más social, la justicia. El hombre moral de nuestro tiempo, y muy en particular el cristiano, debe tomar sobre sí, como principal, la tarea de la lucha por la justicia. Nadie puede permanecer ya neutral ante su demanda. El que no milita en pro de la justicia, en realidad ha elegido, inhibitoriamente, que es la peor manera de elegir, la injusticia. La conciencia y asunción de todas nuestras responsabilidades es una de las virtudes más necesarias al hombre de hoy.

44. Ibidem, p. 241. 